November 16, 2009

Cisplatin-Induced Macroautophagy Occurs Prior to Apoptosis in Proximal Tubules In Vivo

by

Kosuke Inoue $^{1}$, Hitoshi Kuwana ${ }^{2}$, Yoshiko Shimamura ${ }^{1}$, Koji Ogata ${ }^{1}$, Yoshinori Taniguchi $^{1}$, Toru Kagawa ${ }^{1}$, Taro Horino ${ }^{1}$, Toshihiro Takao ${ }^{1}$, Tatsuhito Morita ${ }^{1}$, Sei Sasaki $^{2}$, Noboru Mizushima ${ }^{3}$, and Yoshio Terada ${ }^{1}$

From ${ }^{1}$ the Department of Endocrinology, Metabolism and Nephrology, Kochi Medical School, Kochi University, Nankoku 783-8505, the ${ }^{2}$ Department of Nephrology, Tokyo Medical and Dental University, Tokyo 113-8519, Japan

Short title: Autophagy and Apoptosis

KEY WORDS: Autophagy, Apoptosis, Cisplatin, acute kidney injury

Word count for abstract: 232 words

Word count for text: 3560 words

Address correspondence and reprint requests to:

Yoshio Terada, M.D.

The Department of Endocrinology, Metabolism and Nephrology, Kochi Medical School, Kochi University, Kohasu, Oko-cho, Nankoku, Kochi 783-8505, Japan

Tel: $81-88-880-2341$

Fax: 81-88-880-2344

E-Mail: terada@kochi-u.ac.jp 


\begin{abstract}
Background. Autophagy is an intracellular bulk degradation process induced by cell starvation. Autophagy was recently reported to be induced by various stresses such as hypoxia, ischemia/reperfusion, toxins, and denatured proteins, and to affect cell survival and death. Light chain 3-II (LC3-II) is specifically located on double membrane-bound autophagosomes that envelop disused proteins or organelles.
\end{abstract}

Method. Transgenic mice in which green fluorescent protein (GFP) was fused to LC3 (LC3-GFP) were administered cisplatin $(20 \mathrm{mg} / \mathrm{kg})$. After euthanasia at times between 0-72 hours, kidneys were excised for immunohistochemical analyses. Microscopic examinations of the generated NRK-52E cell lines stably transfected with LC3-GFP, and western blot analyses of NRK-52E cells were undertaken after cisplatin treatment with or without autophagy inhibitors and beclin 1 siRNA.

Results. Autophagosomes increased in the proximal tubular cells of transgenic mice from 12 hours after cisplatin injection $(20 \mathrm{mg} / \mathrm{kg})$. The time course for this was faster than those for tubular necrosis and apoptosis. Autophagosomes also increased in NRK-52E cells after cisplatin treatment, with the time course for this faster than that for apoptosis. When autophagy was suppressed by autophagy inhibitors or beclin 1 siRNA, the level of apoptosis was also suppressed.

Conclusion. Autophagy occurs in proximal tubular cells after cisplatin treatment and is involved in cell death in renal tubular injury. Our data suggested that autophagy is a kind of cell damage index and cells with activated autophagy will be scavenged by apoptosis. 


\section{Introduction}

Eukaryotes have two major systems for degrading proteins: the ubiquitin-proteasome system and autophagy. The ubiquitin-proteasome system degrades short-lived and selective proteins. Autophagy degrades long-lived and non-selective proteins in large amounts and cell organelles. Autophagy is induced by starvation, changes in cell volume, oxidative stress, accumulation of misfolded proteins, hormonal signaling, irradiation and xenobiotic treatment $[1,2]$, and the roles of autophagy have been suggested to include nutrition, recycling of amino acids, purification and cellular defense against bacteria. Macroautophagy is the most common form of autophagy, progressing through double-membrane autophagosomes. The discovery of autophagy-related proteins in yeast has revealed the existence of an evolutionarily conserved mechanism for the formation of autophagosomes that sequester cytoplasmic material before they fuse with the endo/lysosomal compartment [3,4]. Light chain 3-II (LC3-II) is specifically located on double membrane-bound autophagosomes that envelop disused proteins or organelles. LC3-II is a good marker for autophagic membranes. Mizushima et al. confirmed that over-expression of a fusion protein between green fluorescent protein and light chain 3 (LC3-GFP) does not affect endogenous autophagy, and generated transgenic mice that systemically expressed this fusion protein (LC3-GFP mouse). Autophagosomes can be recognized as ring-shaped structures by fluorescence microscopy. Using these transgenic mice, autophagy in mouse tissues can be directly monitored by simply creating cryosections and subsequent fluorescence microscopy [5].

In neurodegenerative disorders, autophagy has been shown to contribute to the elimination of misfolded accumulated proteins [1,2]. Autophagy is induced in variant cancer cells in response to anticancer therapies, in some cases promotes cell survival 
and in other cases induces apoptosis or type-2 programmed cell death [6-8]. Chronic myocardial ischemia/reperfusion injury induces autophagy increment and apoptosis decrement [9]. Inhibition of autophagy prevents neuron death after hypoxic-ischemic injury in neonatal mice [10]. However, in acute kidney injury (AKI), the association between autophagy and cell death is not obvious.

Cisplatin is a major chemotherapeutic drug against solid tumors. One of the most important side effects of cisplatin is nephrotoxicity. Cisplatin is freely filtered at the glomerulus and taken up by renal tubular cells. There are many signaling cascades leading from cisplatin administration to AKI, for example, decreasing renal blood flow, levels of free radical scavengers, regulating expression of genes, increasing the numbers of inflammatory cells and levels of caspase-dependent apoptosis. Recently, the level of apoptosis was found to be related to the degree of seriousness of AKI [11].

The purpose of this study was to investigate the roles of autophagy in tubule cells in AKI to identify a procedure that modifies kidney damage. Our results indicated that cisplatin induces autophagy in proximal tubular cells in vivo. Inhibition of autophagy led to down-regulation of cisplatin-induced apoptosis in proximal tubular cells in vitro. Autophagy inhibitors may serve as therapeutic targets for the treatment of AKI.

\section{Subjects and Methods}

\section{Materials}

Anti-light chain 3 antibody was purchased from MBL (Nagoya, Japan). Anti-aquaporin-1 antibody was purchased from Abcam (Cambridge, MA). Anti-cleaved caspase 3 and rapamycin were purchased from Cell Signaling (Danvers, 


\begin{abstract}
MA), anti-beclin 1 was purchased from BD Bioscience (Franklin Lakes, NJ), Lipofectamine $^{\mathrm{TM}} 2000$ was purchased from Invitrogen (Carlsbad, CA), 3-methyladenine (3-MA) was purchased from SIGMA (Saint Louis, MI), [L-3-trans-ethoxycarbonyloxirane-2-carbony1]-L-leucine (3-methylbutyl) amide (E64d) and isovaleryl-L-Val-L-Val-AHMHA-L-Ala-AHMHA (pepstatin A) were purchased from PEPTIDE INSTITUTE, INC, (Osaka, Japan). Can Get Signal ${ }^{\mathrm{TM}}$ was purchased from TOYOBO (Osaka, Japan).
\end{abstract}

\title{
Animal Preparation
}

All experimental procedures were performed according to the guidelines for the care and use of animals established by Tokyo Medical and Dental University. Male transgenic mice that systemically expressed green fluorescent protein fused to light chain 3 (LC3-GFP mice; kind gift of Noboru Mizushima, Tokyo Medical and Dental University, Japan) [12] aged 21-22 weeks and weighing 35-40 g were used for the experiments. The mice underwent administration of cisplatin $(20 \mathrm{mg} / \mathrm{kg})$; the dose of cisplatin was determined on the basis of the results of previous studies in mice [13]. Kidney samples were harvested at the indicated times. The left kidney was perfused with chilled saline and fixed in $4 \%$ buffered paraformaldehyde for histological examination.

\section{Cell Culture}

The NRK-52E cell line was obtained from ATCC (Manassas, VA), and cultured in DMEM medium containing 10\% fetal bovine serum, 100 units/ml penicillin, and 100 $\mu \mathrm{g} / \mathrm{ml}$ streptomycin at $37^{\circ} \mathrm{C}$ in a $5 \% \mathrm{CO}_{2}$ incubator. In harvesting experiments, the cells were seeded into $10-\mathrm{cm}$ plastic dishes. In fluorescence microscopy experiments, 
the cells were seeded in 35-mm glass-bottomed dishes. The LC3-GFP plasmid (kind gift of Noboru Mizushima, Tokyo Medical and Dental University, Japan) was transfected by electroporation on the basis of the results of previous studies [14]. NRK-52E cells $\left(1.0 \times 10^{7}\right.$ cells) suspended in K-PBS were electroporated (360 V, $960 \mu \mathrm{FD}$ ) using a Gene Pulser (Bio-Rad, New York, NY). After transfection, the cells were cultured in medium containing $1 \mathrm{~g} / \mathrm{L} \mathrm{G} 418$.

\section{Fluorescence Microscopy}

We used an Olympus IX 81 microscope. We labeled tissues on the basis of the results of previous studies [13]. We used an Annexin V-Cy3 Apoptosis Detection Kit purchased from BioVision Research Products (Mountain View, CA) to detect apoptosis in vitro. We washed cells with PBS once, added $100 \mu \mathrm{l}$ of annexin V-Cy3 in binding buffer (1:100) for 5 minutes in the dark, washed with PBS once, added 100 $\mu \mathrm{l}$ of $2 \%$ paraformaldehyde, incubated for 5 minutes in the dark, washed cells with PBS twice, and observed the cells within about 30 minutes.

\section{Beclin 1 Knockdown Using Small Interfering RNA}

A beclin 1 small interfering RNA (siRNA) and scrambled siRNA were purchased from Japan Bio Services Co., LTD. (Saitama, JAPAN). The siRNA sequence against beclin 1 was GAUUGAAGACACAGGAGGC [15]. The sequence of the scrambled siRNA was UCUGAAGAGGGGACCUAUCTT. NRK-52E cells were transfected using Lipofectamine ${ }^{\mathrm{TM}}$ 2000. The control siRNA scrambled siRNA sequence) was used under identical conditions to the beclin 1 siRNA. To determine the efficiency of beclin 1 knockdown, Western blot analyses for beclin 1 were performed. 
NRK-52E cells were transfected with $125 \mathrm{nM}$ siRNA for 4 hours from 56 hours before harvest; after transfection of cells with siRNAs, we changed the medium to DMEM without fetal bovine serum, penicillin and streptomycin for 4 hours. We changed the medium to DMEM containing 10\% fetal bovine serum, but without penicillin and streptomycin, 48 hours before harvest, and administered $10 \mu \mathrm{M}$ cisplatin 24 hours before harvest.

\section{Western Blot Analyses}

Whole cell lysates were extracted from cultured NRK-52E cells lysed in sodium dodecyl sulfate (SDS) sample buffer using previously described methods [13]. Lysate proteins $(60 \mu \mathrm{g} / \mathrm{lane})$ were separated on SDS-polyacrylamide gels and transferred to Hybond-ECL (GE Healthcare, Chicago, IL). The blots were incubated with the indicated antibodies (from 1:500 to 1:2000 dilution) overnight, followed by incubation with horseradish peroxidase-conjugated secondary antibodies (1:3000 dilution) for 1 hour. Membranes were visualized using Western Blue (Promega, San Luis, CA). The intensities of the bands were quantified using Molecular Dynamics ImageQuant software (Sunnyvale, CA). At harvest, the cells were lysed for 30 minutes on ice in $150 \mathrm{mM} \mathrm{NaCl}, 15 \mathrm{mM}$ Tris- $\mathrm{HCl}, 25 \mathrm{mM} \mathrm{NaF}$, and $1 \mathrm{mM} \mathrm{Na} 3 \mathrm{VO}_{4}$ ( $\mathrm{pH} 8.0)$. 


\section{Statistical Analyses}

All values are expressed as means \pm SEM. Statistical comparisons of differences were performed using one- or two-way analysis of variance (ANOVA) combined with the Newman-Keuls post hoc test. $P<0.05$ was considered significant.

\section{Results}

Cisplatin Induces Macroautophagy in Proximal Tubular Cells In Vivo

We first examined the conditions required to induce autophagy and where autophagy was induced using generated transgenic mice that systemically expressed a fusion protein between green fluorescent protein and light chain 3 (LC3-GFP mouse). At 12-48 hours after cisplatin $(20 \mathrm{mg} / \mathrm{kg})$ treatment of LC3-GFP mice, the numbers of autophagosomes were increased in proximal tubular cells compared with those of control mice (Figure 1 and 2). The numbers of autophagosomes were increased from 12 hours, peaked at around 48 hours, and decreased after 72 hours. Immunohistochemistry for aquaporin-1 (AQP1), a marker of proximal tubular cells, revealed that the numbers of autophagosomes were increased in AQP1-positive cells. The change in the number of autophagosomes was not significant in the medulla (Figure 3). We also performed immunohistochemistry for cleaved caspase 3, a marker of the early phase of apoptosis. The increase in the numbers of autophagosomes preceded an increase in the amount of cleaved caspase 3 that was observed 24-48 hours after cisplatin treatment (Figure 4).

\section{Cisplatin Induces Macroautophagy in Cultured Proximal Tubular Cells}

Next, we used NRK52-E cells, a proximal tubular cell line, to investigate the effects of cisplatin in vitro. Hanks' balanced salt solution treatment as a starvation 
condition induced an increase in the numbers of autophagosomes in NRK52-E cells stably transfected with a fusion protein between green fluorescent protein and light chain 3 (LC3-GFP NRK cells) (Figure 5A), and generation of LC3-II in Western blot analyses of protein from non-transfected NRK52-E cells (Figure 5B). Addition of cisplatin to DMEM medium induced an increase in the numbers of autophagosomes and generation of LC3-II to a similar level than the starvation condition. These changes preceded positive staining for annexin $\mathrm{V}$ and cleaved caspase 3 , a marker of the early phase of apoptosis. The generation of LC3-II was increased dose and time dependently up to 48 hours (Figure 6 and 7).

Cisplatin-Induced Apoptosis Is Suppressed by Inhibition of Macroautophagy in Proximal Tubular Cells

To examine the involvement of autophagy in the apoptotic pathway, we employed chemical inhibitors and a stimulator of autophagy. We used 3-methyladenine (3-MA), which is widely used as an autophagy inhibitor, as an inhibitor of autophagosome formation [16]. We also used inhibitors of lysosomal proteases including [L-3-trans-ethoxycarbonyloxirane-2-carbony1]-L-leucine (3-methylbutyl) amide (E64d), a calpain inhibitor, and isovaleryl-L-Val-L-Val-AHMHA-L-Ala-AHMHA (pepstatin A), a cathespsin D inhibitor [17]. On the other hand, rapamycin was used to induce autophagosome formation [18].

We treated LC3-GFP NRK cells with these inhibitors and rapamycin at the same time as adding $40 \mu \mathrm{M}$ cisplatin. Twenty hours after administration, the cisplatin-induced increase in the numbers of autophagosomes was enhanced by rapamycin and E64d/pepstatin A compared with control cells. On the other hand, the cisplatin-induced increase in the numbers of autophagosomes was depressed by 
3-MA compared with control cells. Cisplatin-induced apoptosis was observed as annexin V staining, which was enhanced by rapamycin and suppressed by 3-MA and E64d/pepstatin A (Figure 8).

Furthermore, we examined generation of LC3-II in NRK52-E cells. Similar to the results of fluorescence microscopy, generation of LC3-II was enhanced by rapamycin and E64d/pepstatin A compared with controls. On the other hand generation of LC3-II was depressed by 3-MA compared with controls. At the same time we performed Western blot analyses of cleaved caspase 3 as a marker of cisplatin-induced apoptosis. Levels of cleaved caspase 3 were not changed by rapamycin, but were significantly depressed by 3-MA and E64d/pepstatin A (Figure 9B). In the absence of cisplatin, band intensity of cleaved caspase 3 increased by 3-MA. This increment may reflect cell damage and cell death by 3-MA in this experimental condition.

Cisplatin-Induced Apoptosis Is Suppressed by Specific Inhibition of Macroautophagy by beclin 1 siRNA

To more specifically inhibit autophagy, we used beclin 1 small interfering RNA (siRNA). Beclin 1 is the mammalian homolog of Atg 6 and forms a complex with class III phosphatidylinositol 3-kinase (PI3 kinase) [19]. Beclin 1 siRNA suppressed the production of beclin 1 , and the $10 \mu \mathrm{M}$ cisplatin-induced enhancement of cleaved caspase 3 levels was suppressed significantly by the beclin 1 siRNA (Figure10). 


\section{Discussion}

This is the first study to demonstrate a relationship between macroautophagy and apoptosis in renal tubular cells by fluorescence microscopic examination using the LC3-GFP mouse. We demonstrated the formation of autophagosomes during cisplatin-induced AKI in vivo, and indicated that cisplatin-induced autophagy occurred faster than apoptosis in proximal tubules.

The form of LC3 with a glycine residue at the C-terminal end, termed LC3-I, resides in the cytosol. After activation, the final form of LC3 is designated LC3-II, which associates tightly with the autophagosomal membrane [5]. Because autophagosomes are constantly recycled, and so are transient structures, the lifetime of LC3-II from activation to decomposition is relatively short. The level of LC3-II represents only the autophagic activity at that moment, and does not indicate the quantity of flow through the autophagic pathway. We examined autophagy with or without cisplatin in the presence of E64d and pepstatin A. The numbers of autophagosomes and the amount of LC3-II were increased by cisplatin. We concluded that cisplatin increased flow through the autophagic pathway $[5,17]$.

We demonstrated in this paper that inhibition of autophagy suppressed cisplatin-induced apoptosis. Our data clearly showed that autophagy precedes apoptosis, and that inhibition of autophagy using two inhibitors or beclin 1 siRNA suppressed apoptosis. 3-MA is thought to induce its effects via its activity as a class III PI3 kinase inhibitor [16]; however it is not only a specific inhibitor of macroautophagy, it also has effects on membrane trafficking, alkalinizes the lysosomal lumen, and can inhibit the phosphorylation of JNK and p38 [5]. In the absence of cisplatin, band intensity of cleaved caspase 3 increased by 3-MA as shown in the Figure 9A. This increment may reflect cell damage and cell death by 3-MA, 
because inhibition of autophagy with 3-MA was reported to sensitize HeLa cells to starvation-induced cell death in some condition $[6,15]$. In the presence of cisplatin, levels of cleaved caspase 3 were significantly depressed by 3-MA and E64d/pepstatin A (Figure 9B). Thus we believe that inhibition of autophagy down-regulates cisplatin-induced apoptosis in proximal tubular cells in vitro at least in our experimental conditions.

Furthermore, we performed experiments with the protease inhibitors E64d and pepstatin A, and with beclin 1 siRNA, obtaining similar results.

Why does inhibition of autophagy suppress cisplatin-induced apoptosis? There are many possibilities. In a recent in vivo study, Koike et al. indicated that deficiency of Atg7 prevented hippocampal pyramidal neuron death in hippocampi from neonatal mouse brains after hypoxic-ischemic injury [10]. Also, several studies have reported that autophagy and one or more proapoptotic genes (for example, BAX) collaborate to promote cell death [20-22]. The proapoptotic genes may switch from cell protective autophagy to injurious autophagy promoting cell death. We will investigate the relationships among autophagy, proapoptotic genes and apoptosis in future studies. Why does autophagy yield apoptosis? The inhibition of autophagy increases the mutation rate in yeast [23]. In conditions of chronic stress induced by limited resources (for example, starvation, dehydration and chronic ischemia), scavenging more damaged cells by activating autophagy can reduce the consumption of limited resources. But if the duration of the stress were short, scavenging might eliminate recoverable cells.

Recently, Yang et al. and Periyasamy-Thandavan et al, indicated that inhibition of cisplatin-induced autophagy enhanced cisplatin-induced apoptosis [24, 25]. Their report was the first report to indicate a relationship between autophagy and apoptosis 


\section{Acknowledgements}

This work was supported by the Research fund of Mitsukoshi Health and Welfare foundation, Mochida Memorial foundation, Naito Memorial foundation, and a grant from the Ministry of Education, Science, Culture and Sports of Japan (to Y. T).

\section{References}

1. Alfred JM, Patrice C. Regulation and role of autophagy in mammalian cells. Int $\mathbf{J}$ Biochem Cell Biol 2004; 36: 2445-62

2. Levine B, Kroemer G. Autophagy in the pathogenesis of disease. Cell 2008; 132: $27-42$

3. Yorimitsu T, Klionsky DJ. Autophagy: molecular machinery for self-eating. Cell Death Differ 2005; 12: 1542-52

4. Thorburn A. Apoptosis and autophagy: regulatory connections between two supposedly different processes. Apoptosis 2008; 13: 1-9

5. Mizushima N. Methods for monitoring autophagy. Int J Biochem Cell Biol 2004; 36: $2491-2502$

6. Kondo Y, Kanzawa T, Sawaya R, Kondo S. The role of autophagy in cancer development and response to therapy. Nat Rev Cancer 2005; 5: 726-34

7. Yan $\mathrm{CH}$, Yang YP, Qin ZH, Gu ZL, Reid P, Liang ZQ. Autophagy is involved in cytotoxic effects of crotoxin in human breast cancer cell line MCF-7 cells. Acta Pharmacol Sin 2007; 28: 540-8

8. Ogier-Denis E, Codogno P. Autophagy: a barrier or an adaptive response to cancer. Biochim Biophys Acta 2003; 1603: 113-28 
9. Yan L, Vatner DE, Kim SJ et al. Autophagy in chronically ischemic myocardium. Proc Natl Acad Sci U S A 2005; 102: 13807-12

10. Koike M, Shibata M, Tadakoshi M et al. Inhibition of autophagy prevents hippocampal pyramidal neuron death after hypoxic-ischemic injury. Am J Pathol 2008; 172: 454-69

11. Yao X, Panichpisal K, Kurtzman N, Nugent K. Cisplatin nephrotoxicity: a review. Am J Med Sci 2007; 334: 115-24

12. Mizushima N, Yamamoto A, Matsui M, Yoshimori $\mathrm{T}$, Ohsumi $\mathrm{Y}$. In vivo analysis of autophagy in response to nutrient starvation using transgenic mice expressing a fluorescent autophagosome marker. Mol Biol Cell 2004; 15: 1101-11

13. Kuwana $\mathrm{H}$, Terada $\mathrm{Y}$, Kobayashi $\mathrm{T}$ et al. The phosphoinositide-3 kinase gamma-Akt pathway mediates renal tubular injury in cisplatin nephrotoxicity. Kidney Int 2008; 73: 430-45

14. Kobayashi T, Tanaka H, Kuwana $\mathrm{H}$ et al. Wnt4-transformed mouse embryonic stem cells differentiate into renal tubular cells. Biochem Biophys Res Commun 2005; 336: 585-95

15. Boya $\mathrm{P}$, Gonzalez-Polo RA, Casares $\mathrm{N}$ et al. Inhibition of macroautophagy triggers apoptosis. Mol Cell Biol 2005; 25: 1025-40

16. Levine B, Yuan J. Autophagy in cell death: an innocent convict? J Clin Invest 2005; $115: 2679-88$

17. Tanida I, Minematsu-Ikeguchi N, Ueno T, Kominami E. Lysosomal turnover, but not a cellular level, of endogenous LC3 is a marker for autophagy. Autophagy 2005; $1: 84-91$ 
18. Ravikumar B, Vacher $\mathrm{C}$, Berger $\mathrm{Z}$ et al. Inhibition of mTOR induces autophagy and reduces toxicity of polyglutamine expansions in fly and mouse models of Huntington disease. Nat Genet 2004; 36: 585-95

19. Codogno P, Meijer AL. Autophagy and signaling: their role in cell survival and cell death. Cell Death Differ 2005; 12: 1509-18

20. Crighton D, Wilkinson S, O'Prey J et al. DRAM, a p53-induced modulator of autophagy, is critical for apoptosis. Cell 2006; 126: 121-34

21. Berry DL, Baehrecke EH. Growth arrest and autophagy are required for salivary gland cell degradation in Drosophila. Cell 2007; 131: 1137-48

22. Lockshin RA, Zakeri Z. Apoptosis, autophagy, and more. Int Biochem Cell Biol 2004; 36: 2405-19

23. Tsujimoto Y, Shimizu S. Another way to die: autophagic programmed cell death. Cell Death Differ 2005; 12: 1528-34

24. Yang C, Kaushal V, Shah SV, Kaushal GP. Autophagy is associated with apoptosis in cisplatin injury to renal tubular epithelial cells. Am J Physiol Renal Physiol 2008; 294: 777-87

25. Periyasamy-Thandavan S, Jiang M, Wei Q, Smith R, Yin X, Dong Z. Autophagy is cytoprotective during cisplatin injury of renal proximal tubular cells. Kidney Int 2008; 74:631-40.

26. Stein RC. Prospects for phosphoinositide 3-kinase inhibition as a cancer treatment. Endocr Relat Cancer 2001; 8: 237-48

27. Sarro E, Tornavaca O, Plana M, Mesequer A, Itarte E. Phosphoinositide 3-kinase inhibitors protect mouse kidney cells from cyclosporine-induced cell death. Kidney Int $2008 ; 73: 77-85$ 


\begin{abstract}
28. Suzuki C, Isaka Y, Takabatake Y, Tanaka H, Koike M, Shibata M, Uchiyama Y, Takahara S, Imai E. Participation of autophagy in renal ischemia/reperfusion injury. Biochemical and Biophysical Research Communication 2008; 368:100-6
\end{abstract}

\title{
Figure Legends
}

Figure 1. Time course of cisplatin-induced macroautophagy in the cortex in vivo. Transgenic mice expression a fusion protein between green fluorescent protein and light chain 3 (LC3-GFP mice) underwent $20 \mathrm{mg} / \mathrm{kg}$ cisplatin administration. Kidney samples were harvested at $0,12,24,48$ and 72 hours after cisplatin administration. The upper panels show low-power views (original magnification $\mathrm{x} 400$ ), and the lower panels show high-power views (original magnification x600). The arrows indicate the autophagosomes. Autophagosomes increased from 12 hours, peaked at 48 hours, and decreased after 72 hours. At 48 hours after cisplatin administration, kidneys showed severe loss of tubular epithelial cells.

Figure 2. Cortex immunostained for AQP1 after cisplatin administration in vivo. Transgenic mice underwent $20 \mathrm{mg} / \mathrm{kg}$ cisplatin administration. Kidney samples were harvested at 0 and 24 hours after cisplatin administration. (A) Zero hours after cisplatin administration. (B) Twenty-four hours after cisplatin administration. Left panels indicate autophagosomes containing LC3-GFP. The arrows indicate the autophagosomes. Center panels show immunostaining with anti-aquaporin-1 (anti-AQP1) antibody. The arrows indicate AQP1-positive cells. Right panels show merges (original magnification $\mathrm{x} 400$ and $\mathrm{x600)}$ ). Positive staining for AQP1 was detected at proximal tubular cells. Proximal tubular cells with strong injury showed decreased AQP1 expression 24 hours after cisplatin administration. (C) Higher 
magnification view of the cortex labeled with anti-AQP1 antibody 24 hours after cisplatin administration. Autophagosomes were present in proximal tubular cells 24 hours after cisplatin administration.

Figure 3. Medulla labeled with an antibody against AQP1 after cisplatin administration in vivo. Transgenic mice underwent $20 \mathrm{mg} / \mathrm{kg}$ cisplatin administration. Kidney samples were harvested at 0 and 24 hours after cisplatin administration. (A) Zero hours after cisplatin administration. (B) Twenty-four hours after cisplatin administration. Left panels indicate autophagosomes containing LC3-GFP. Center panels show immunostaining with anti-AQP1 antibody. Right panels show merges (original magnification $\mathrm{x} 400$ and $\mathrm{x} 600$ ). No cells showed an increase in the numbers of autophagosomes after cisplatin administration.

Figure 4. Time course of cisplatin-induced macroautophagy and staining with anti-cleaved caspase 3 antibody in cortex in vivo. Transgenic mice underwent 20 $\mathrm{mg} / \mathrm{kg}$ cisplatin administration. Kidney samples were harvested at 0, 12, 24, 48 and 72 hours after cisplatin administration. Upper panels indicate autophagosomes with LC3-GFP. The arrows indicate the autophagosomes. Center panels show immunostaining with anti-cleaved caspase 3 antibody. The arrows indicate cleaved caspase 3-positive cells. Lower panels show merges (original magnification x400). Positive staining of cleaved caspase 3 was detected in cells in the early phase of apotosis. The increase in the numbers of autophagosomes was seen from 12 hours after cisplatin administration. Cells with positive cleaved caspase 3 staining were seen 24-48 hours after cisplatin administration. 
Figure 5. Hanks' balanced salt solution treatment as a starvation condition induced autophagy in proximal tubular cells in vitro. (A) NRK52-E cells stably transfected with a fusion protein between green fluorescent protein and light chain 3 were treated with Hanks' balanced salt solution for 0 or 30 minutes. Hanks' balanced salt solution treatment induced an increase in the numbers of autophagosomes (original magnification x400). (B) Western blots of protein from NRK52-E cells treated with Hanks' balanced salt solution for 0 or 2 hours, with or without [L-3-trans-ethoxycarbonyloxirane-2-carbony1]-L-leucine (3-methylbutyl) amide (E64d) and isovaleryl-L-Val-L-Val-AHMHA-L-Ala-AHMHA (pepstatin A). Hanks' balanced salt solution treatment induced generation of LC3-II.

Figure 6. Addition of cisplatin to DMEM medium induced autophagy in LC3-GFP stably transfected proximal tubular cells in vitro. NRK52-E cells stably transfected with a fusion protein between green fluorescent protein and light chain 3 were treated with $40 \mu \mathrm{M}$ cisplatin for $0,3,6$ (early phase), 12, 24 or 48 (late phase) hours before observation. The upper panels indicate autophagosomes containing LC3-GFP. The arrows indicate the autophagosomes. Center panels show staining with anti-annexin V antibody. The arrows indicate annexin V-positive cells. Lower panels show merges (original magnification $\mathrm{x} 400$ ). The increase in the numbers of autophagosomes occurred from 3 or 6 hours after cisplatin treatment. Positive staining for annexin $\mathrm{V}$ at membrane surface was detected from 12 hours.

Figure 7. Addition of cisplatin to DMEM medium induced autophagy in proximal tubular cells in vitro in Western blot analysis. (A) Western blots of protein from NRK52-E cells treated with $18 \mu \mathrm{M}$ cisplatin for $0,12,24$ or 48 hours before harvest. 
The generation of LC3-II was increased time dependently up to 48 hours. The cleaved caspase 3 was increased time dependently up to 48 hours. (B) Western blots of protein from NRK52-E cells treated with cisplatin at $0,7.5,10,15$ or $20 \mu \mathrm{M}$ for 48 hours. The generation of LC3-II was increased dose dependently. The cleaved caspase 3 was increased dose dependently.

Figure 8. Cisplatin-induced apoptosis was suppressed by inhibition of macroautophagy in LC3-GFP stably transfected proximal tubular cells in vitro. (A) NRK52-E cells stably transfected with a fusion protein between green fluorescent protein and light chain 3 were treated with rapamycin $(100 \mathrm{nM}), 3$-methyladenine (3-MA) $(10 \mathrm{mM})$, or E64d $(29.6 \mu \mathrm{M})$ /pepstatin A $(14.6 \mu \mathrm{M})$ for 20 hours without cisplatin. There was an increase in the numbers of autophagosomes in cells treated with rapamycin or E64d/pepstatin A, but no cells showed positive staining for annexin $\mathrm{V}$ at the membrane surface without cisplatin. (B) NRK52-E cells stably transfected with a fusion protein between green fluorescent protein and light chain 3 were treated with rapamycin $(100 \mathrm{nM}), 3-\mathrm{MA}(10 \mathrm{mM})$, or E64d $(29.6 \mu \mathrm{M}) /$ pepstatin A $(14.6 \mu \mathrm{M})$ for 20 hours and with cisplatin $(40 \mu \mathrm{M})$ for 20 hours before observation. The increase in the number of autophagosomes was enhanced by rapamycin and E64d/pepstatin A, and depressed by 3-MA compared with controls. The positive staining for annexin $\mathrm{V}$ at the membrane surface was enhanced by rapamycin and suppressed by 3-MA and E64d/pepstatin A. (A and B) Upper panels indicate autophagosomes containing LC3-GFP. The arrows indicate the autophagosomes. Center panels show staining with anti-annexin $\mathrm{V}$ antibody. The arrows indicate annexin V-positive cells. Lower panels show merges (original magnification x400). 
Figure 9. Cisplatin-induced apoptosis is suppressed by inhibition of macroautophagy in proximal tubular cells in vitro in Western blot analyses. (A) Western blots of protein from NRK52-E cells treated with rapamycin (100 nM), 3-MA (10 mM), or E64d $(29.6 \mu \mathrm{M})$ /pepstatin A $(14.6 \mu \mathrm{M})$ for 24 hours without cisplatin. (B) Graph summaries of Figure 9A using a densitometer. Each bar represents the mean \pm SEM. (C) Western blots of protein from NRK52-E cells treated with rapamycin $(100 \mathrm{nM})$, 3-MA (10 mM), or E64d (29.6 $\mu \mathrm{M})$ /pepstatin A (14.6 $\mu \mathrm{M})$ for 24 hours with $18 \mu \mathrm{M}$ cisplatin. The generation of LC3-II was enhanced by rapamycin, and E64d/pepstatin A, and depressed by 3-MA compared with controls. (D) Graph summaries of Figure 9C using a densitometer. Each bar represents the mean \pm SEM $(\mathrm{n}=5) .{ }^{*} P<0.01$ vs. only cisplatin. Cleaved caspase 3 was unchanged by rapamycin, and significantly depressed by 3-MA and E64d/pepstatin A.

Figure 10. Cisplatin-induced apoptosis is suppressed by specific inhibition of macroautophagy by beclin 1 siRNA in vitro. (A) Western blots of protein from NRK52-E cells treated with scrambled siRNA or beclin 1 siRNA. Beclin 1 siRNA suppressed the expression of beclin 1. Graph summaries of Western blots using a densitometer are also shown. Each bar represents the mean \pm SEM $(n=4) .{ }^{*} P<0.01$ vs. control. (B) Western blots of protein from NRK52-E cells treated with scrambled siRNA or beclin 1 siRNA with or without $10 \mu \mathrm{M}$ cisplatin, and graph summaries of Western blots using a densitometer. Each bar represents the mean $\pm \operatorname{SEM}(\mathrm{n}=4) .{ }^{*} P$ $<0.05$ vs. control plus cisplatin. The cisplatin-induced enhancement of cleaved caspase 3 was suppressed by beclin 1 siRNA. 
Figure
Clidriggetbrownoad FGoretëgure02.ppt

A Control

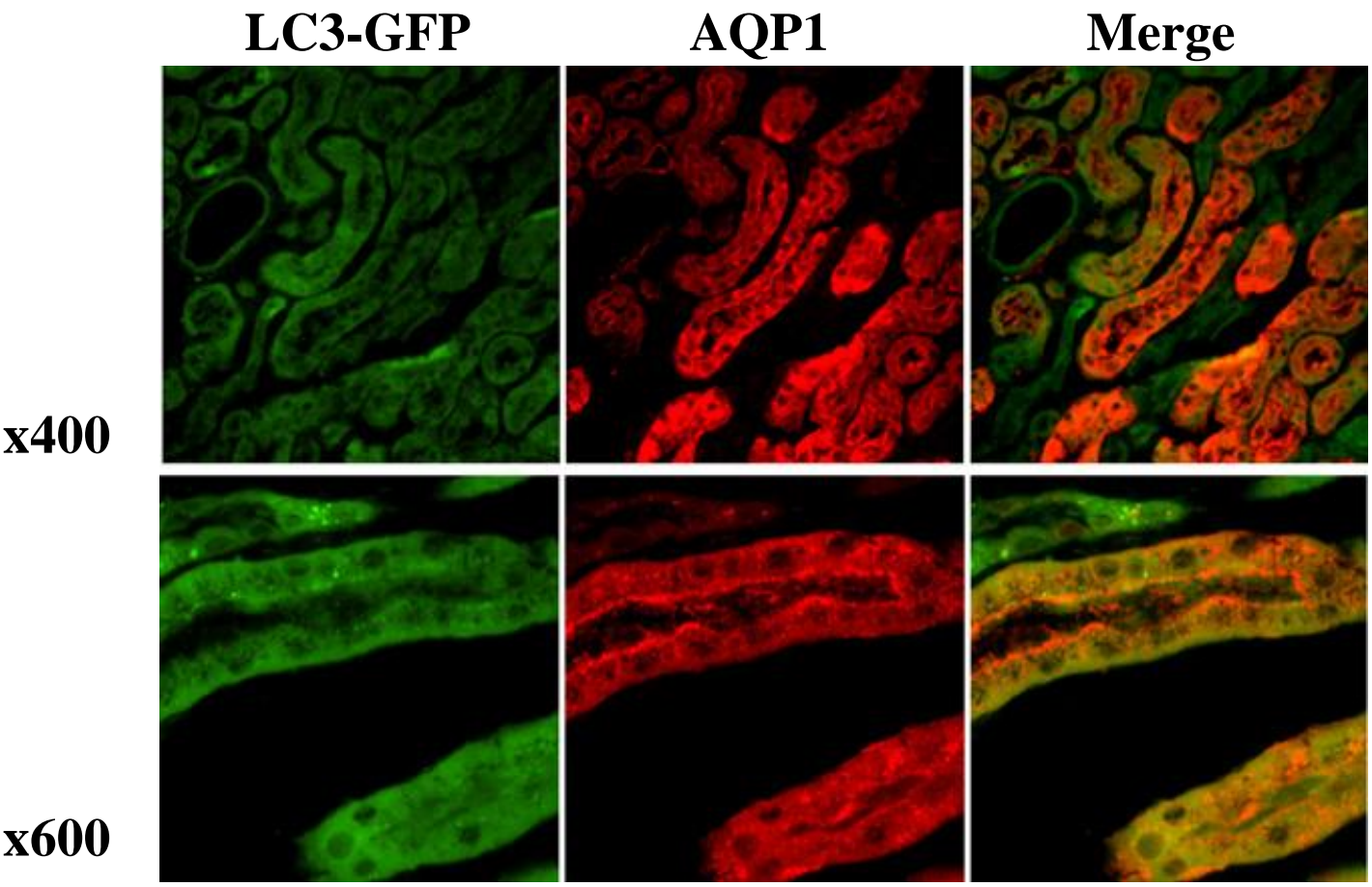

B

AKI ( 24 hours after cisplatin administration ) LC3-GFP

AQP1

Merge

x400
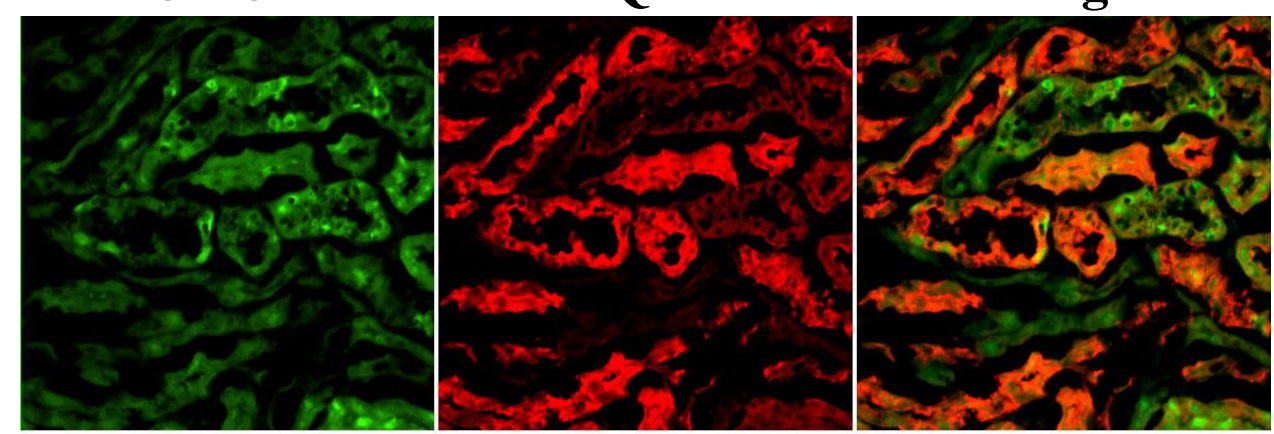

x600
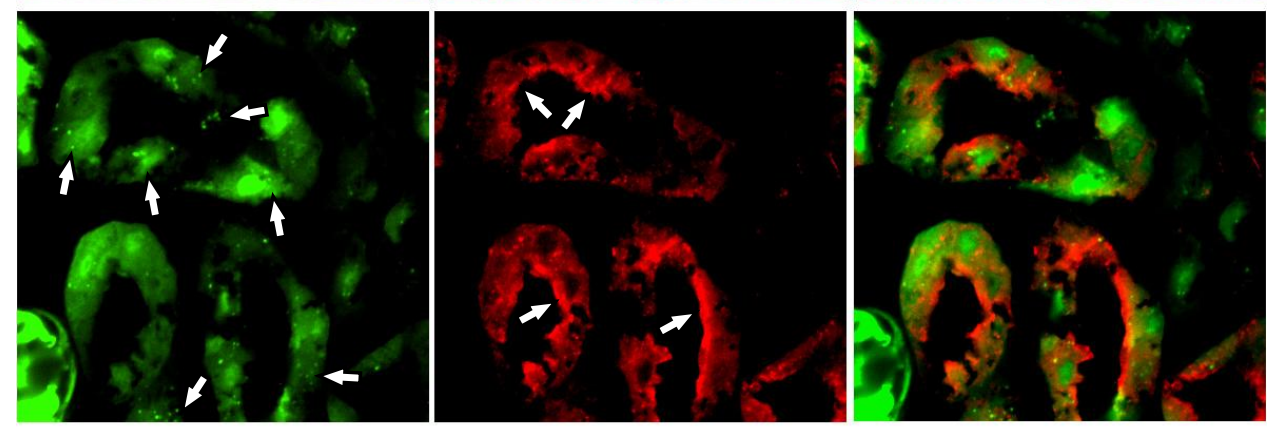

C

Higher magnification

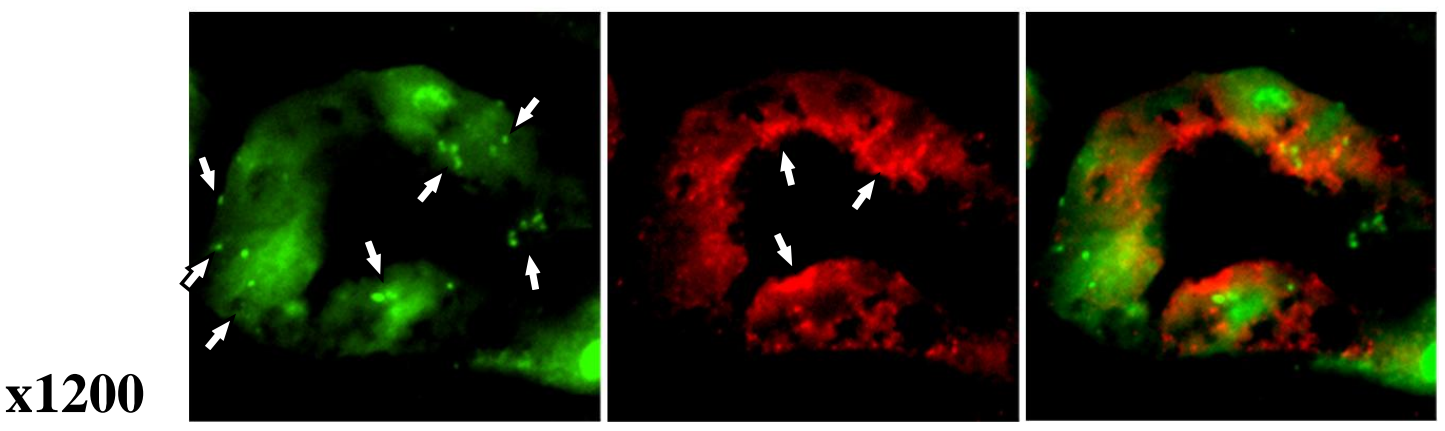




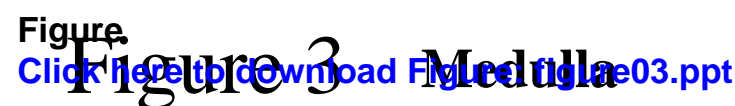

A

Control
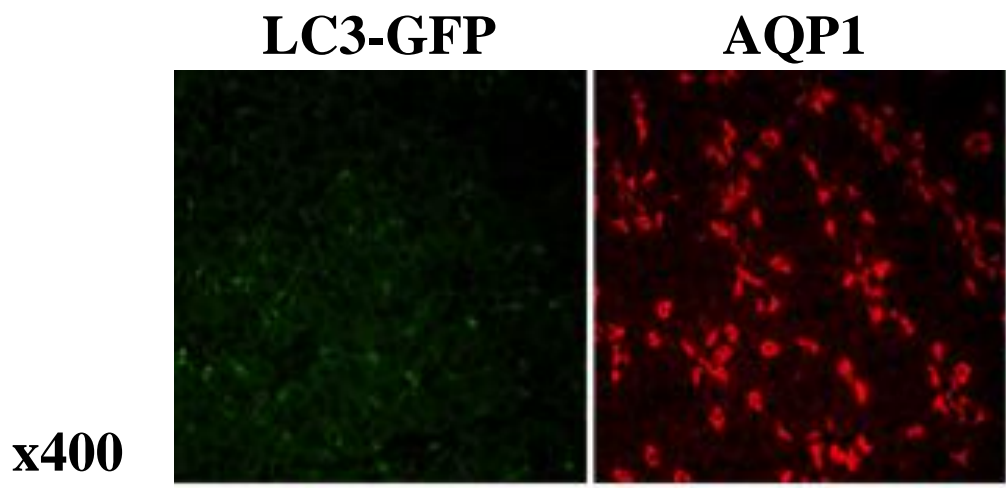

Merge
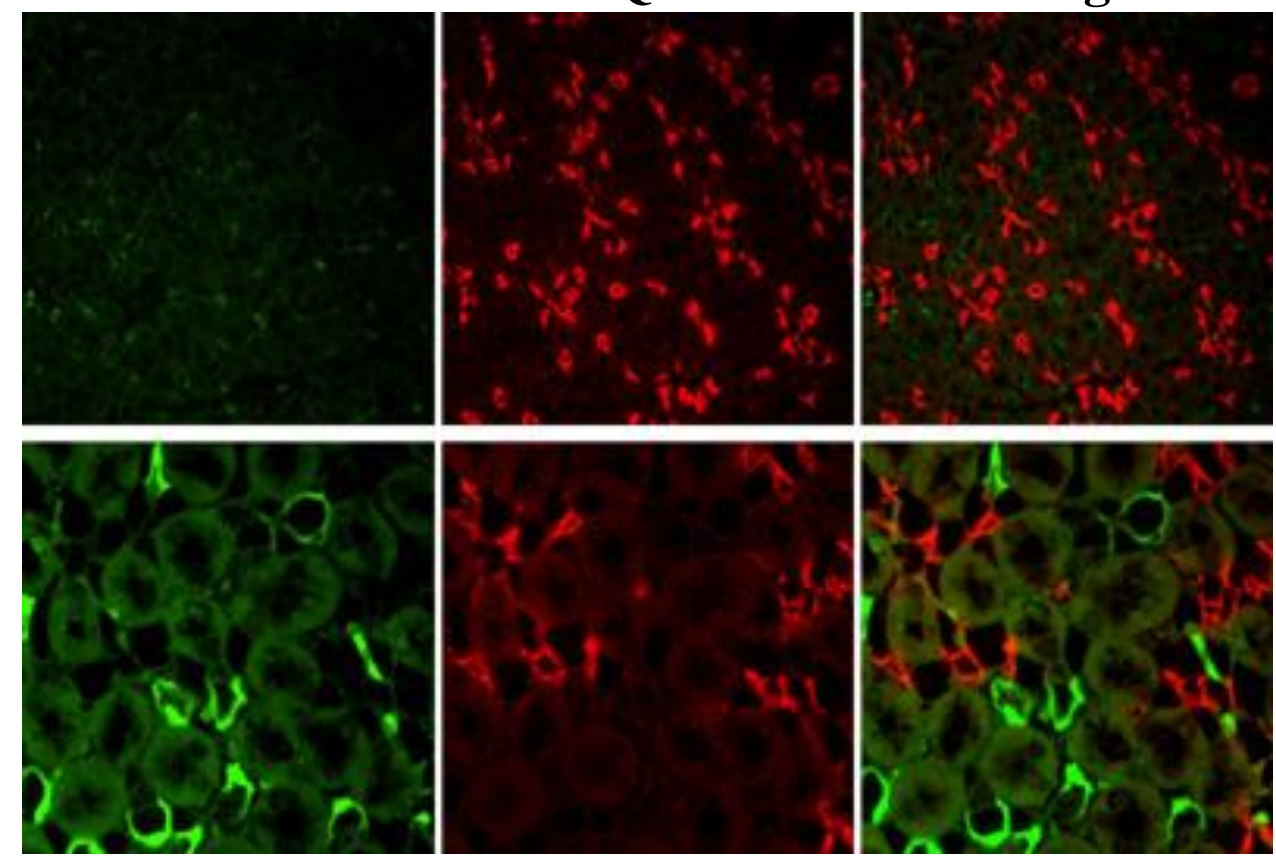

B

AKI ( 24 hours after cisplatin administration ) LC3-GFP AQP1 Merge

$\mathrm{x} 400$
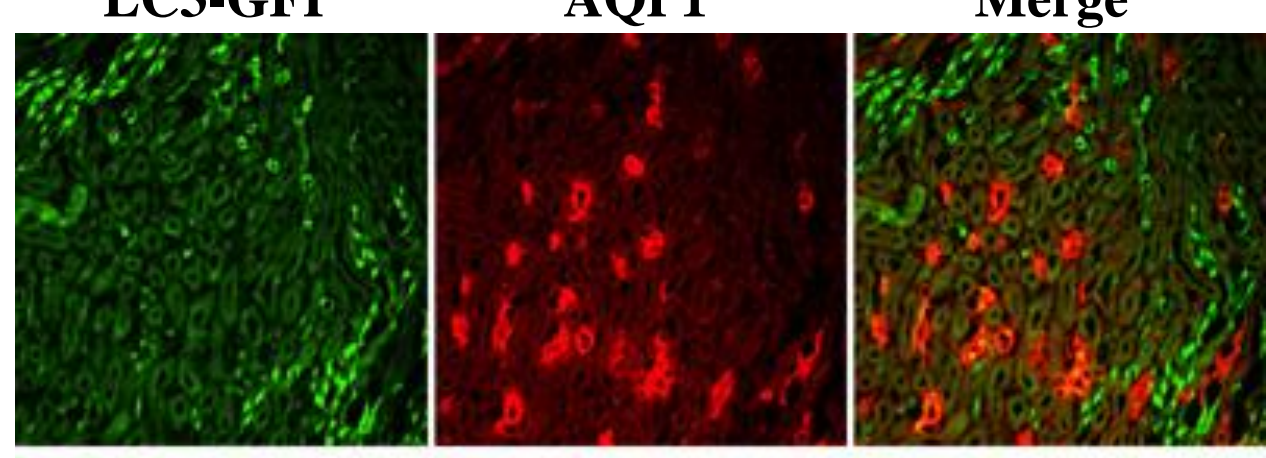

x600
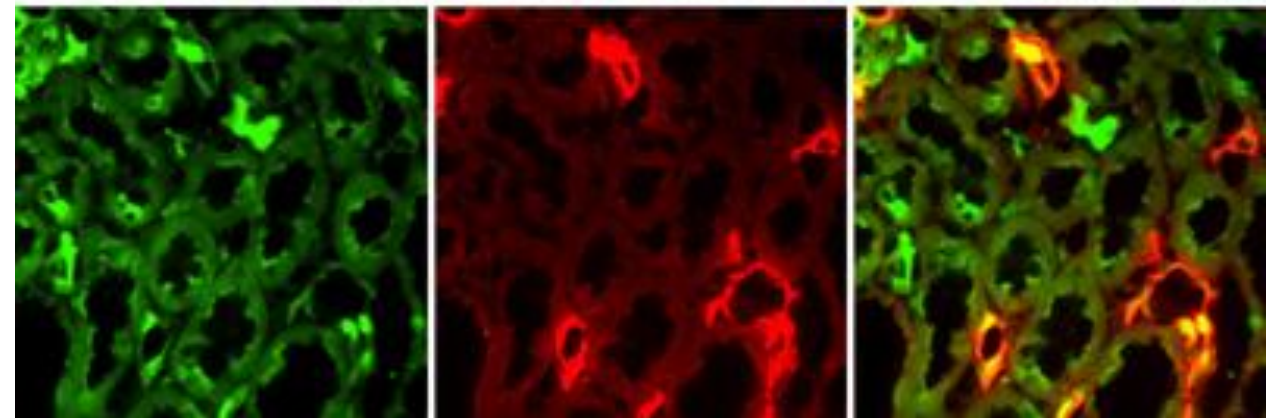
Figure
Click here to download Figure: figure04.ppt

Figure 4

Time after cisplatin administration

$\begin{array}{lll}0 \mathrm{~h} & 12 \mathrm{~h} & 24 \mathrm{~h}\end{array}$

LC3-GFP
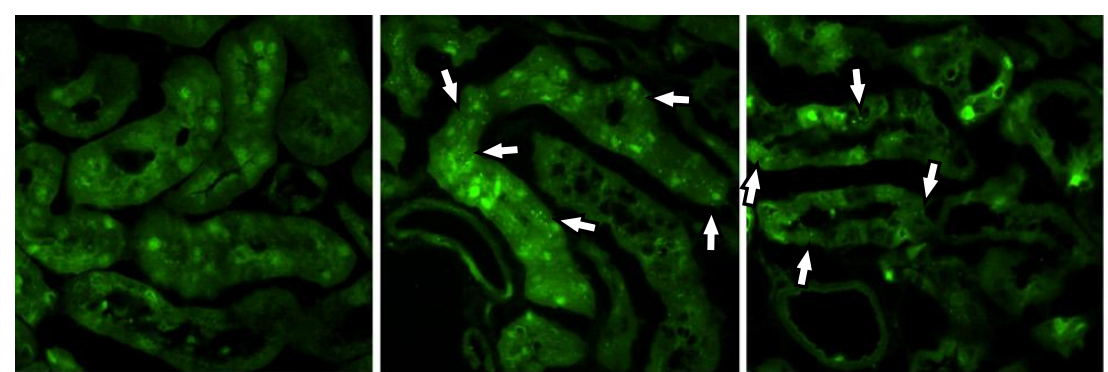

$48 \mathrm{~h}$

$72 \mathrm{~h}$

\section{cleaved caspase 3}
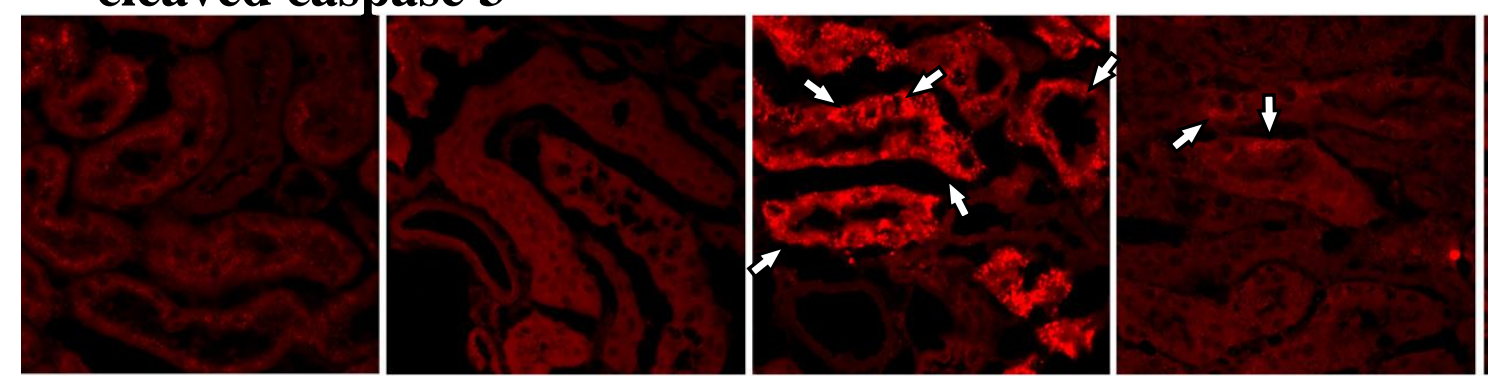

$\mathrm{x400}$

merge
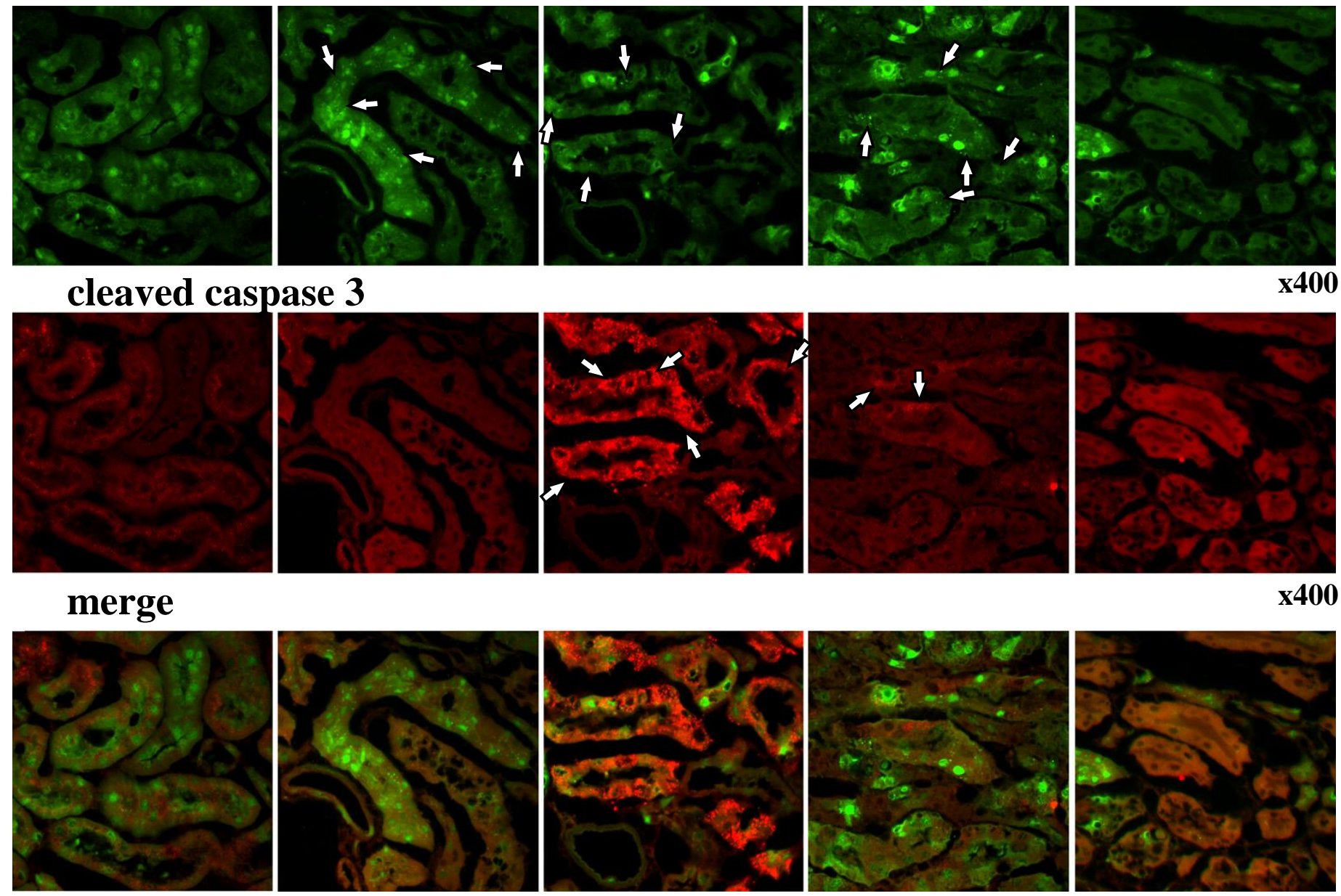

$\mathrm{x} 400$ 
Click here to download Figure: figure05.ppt Figure 5

A
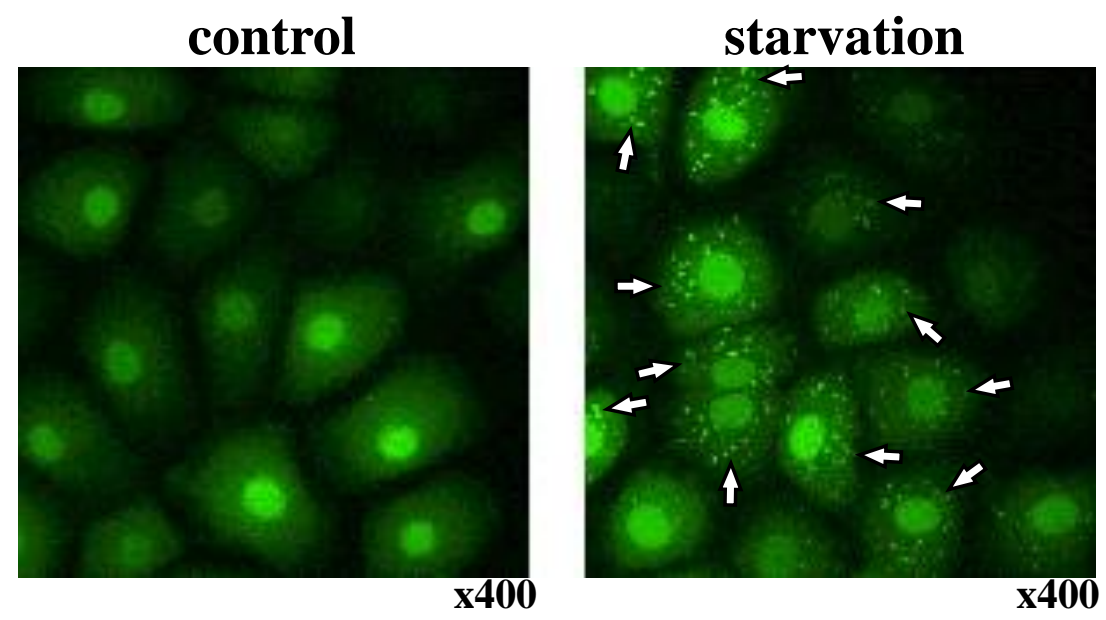

B

\begin{tabular}{|c|cccc|}
\hline DMEM & + & - & + & - \\
\hline Hanks buffer 2 h & - & + & - & + \\
\hline E64d/pepstatinA 2 h & - & - & + & + \\
\hline
\end{tabular}

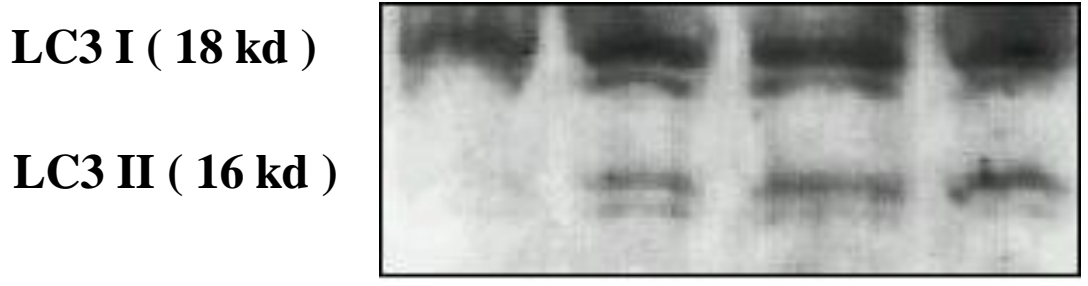

$\operatorname{actin}(42 \mathrm{kd})$

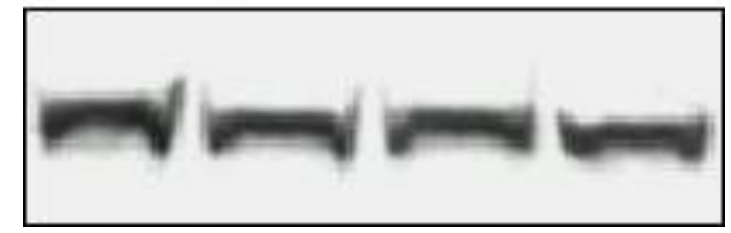




\section{Figure}

Click bere to download Figure: figure06.ppt

F1gure 6

Time after cisplatin administration

early phase

LC3-GFP

annexin $\mathrm{V}$

merge
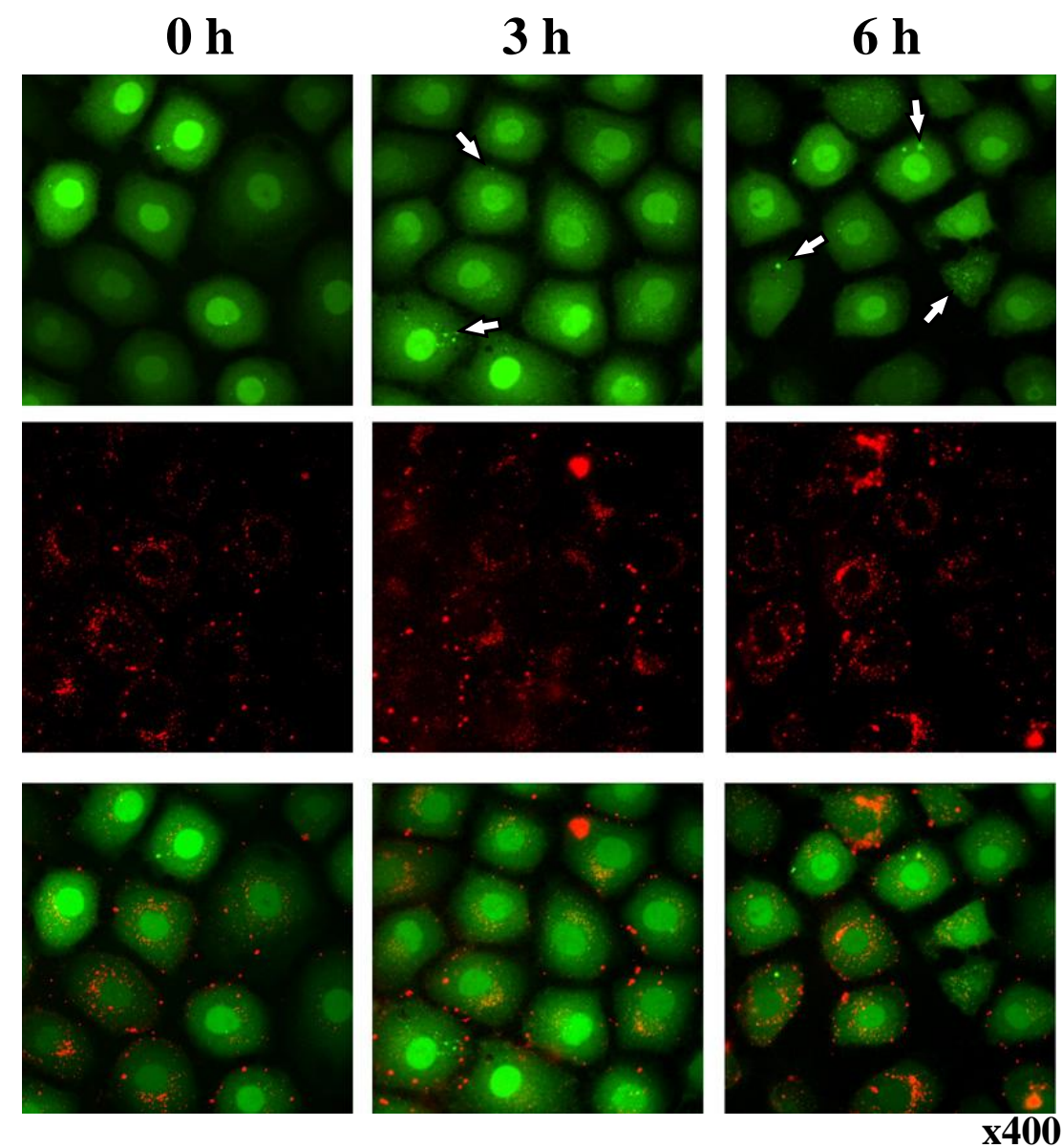

late phase

$12 \mathrm{~h}$

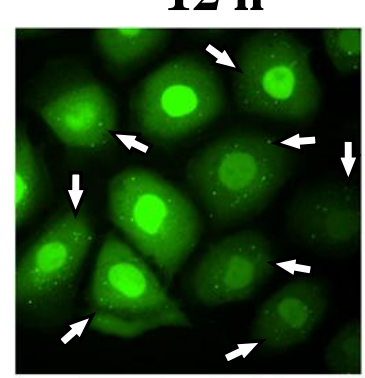

$24 \mathrm{~h}$

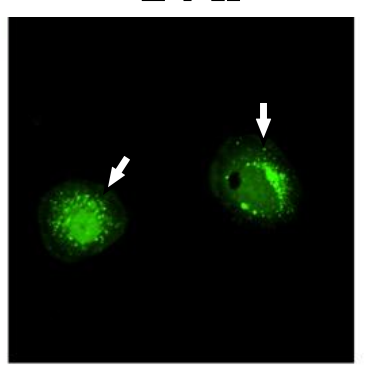

$48 \mathrm{~h}$

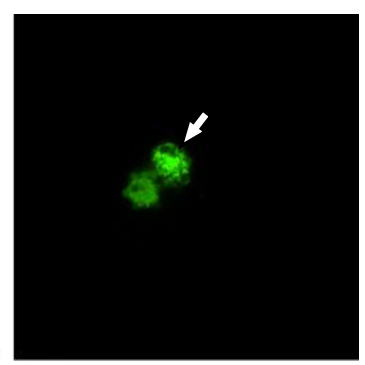

annexin $\mathrm{V}$
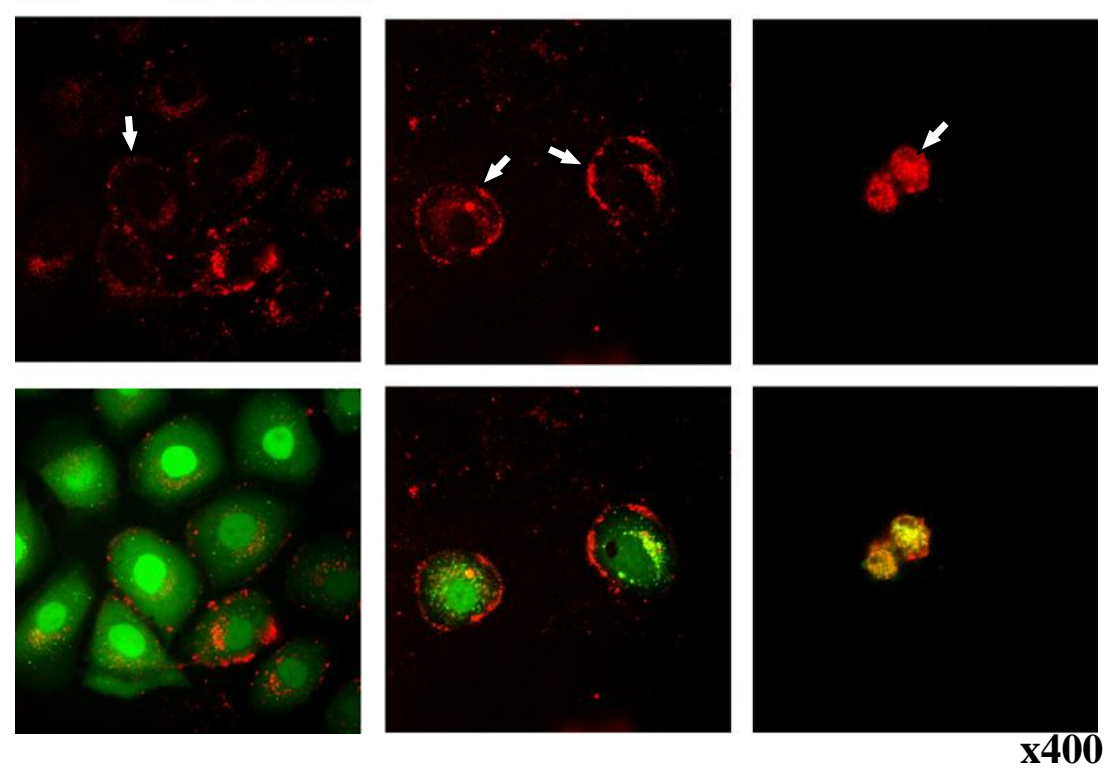
Figure
Click here to download Figure: figure07.ppt

Figure 7

A

\begin{tabular}{|c|llll|}
\hline $\begin{array}{c}\text { after cisplatin administration } \\
\text { ( hour ) }\end{array}$ & 0 & 12 & 24 & 48 \\
\hline
\end{tabular}

LC3 I ( 18 kd )

LC3 II ( 16 kd )

cleaved caspase 3 ( $17 \mathrm{kd}$ )

actin ( $42 \mathrm{kd}$ )

B

\begin{tabular}{|l|lllll|}
\hline cisplatin $(\mu \mathrm{M})$ & 0 & 7.5 & 10 & 15 & 20 \\
\hline
\end{tabular}

\section{LC3 I ( 18 kd ) \\ LC3 II ( 16 kd )}

cleaved caspase 3 ( $17 \mathrm{kd}$ )

actin ( 42 kd )
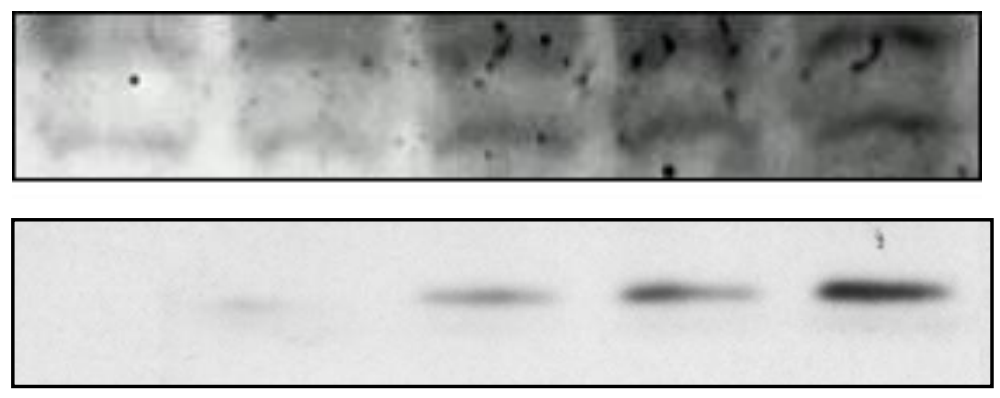
A

\begin{tabular}{|c|cccc|}
\hline cisplatin & - & - & - & - \\
\hline rapamycin & - & + & - & - \\
\hline 3-MA & - & - & + & - \\
\hline E64d/pepstatinA & - & - & - & + \\
\hline
\end{tabular}

\section{LC3 I ( 18 kd )}

LC3 II ( 16 kd )

cleaved caspase 3

( 17 kd )

$\operatorname{actin}(42 \mathrm{kd}$ )
B

Densitometric analysis of cleaved caspase 3

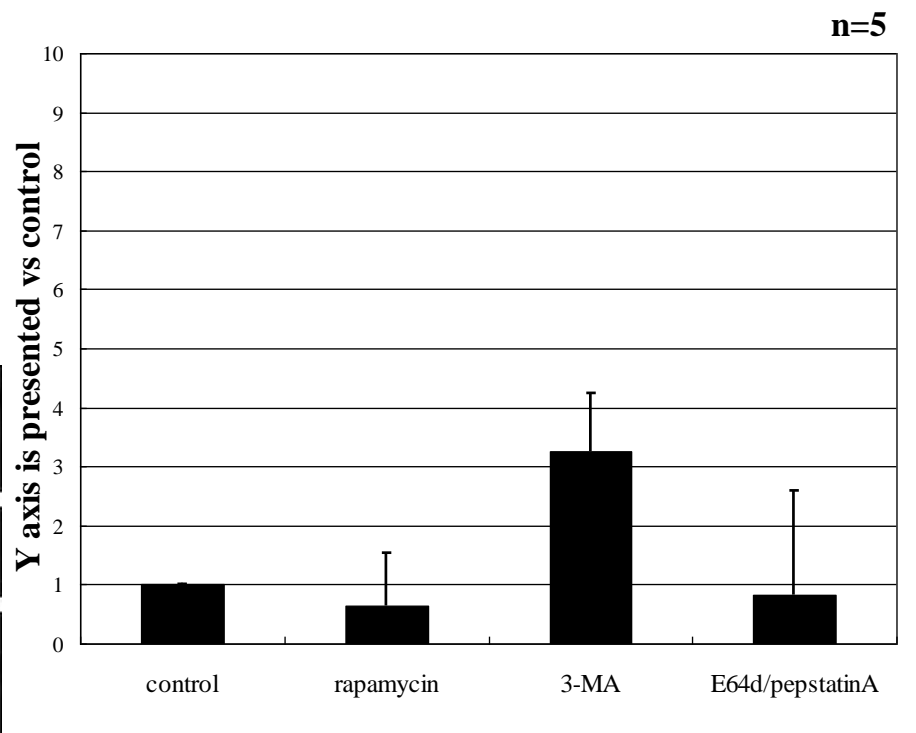

D

Densitometric analysis of cleaved caspase 3

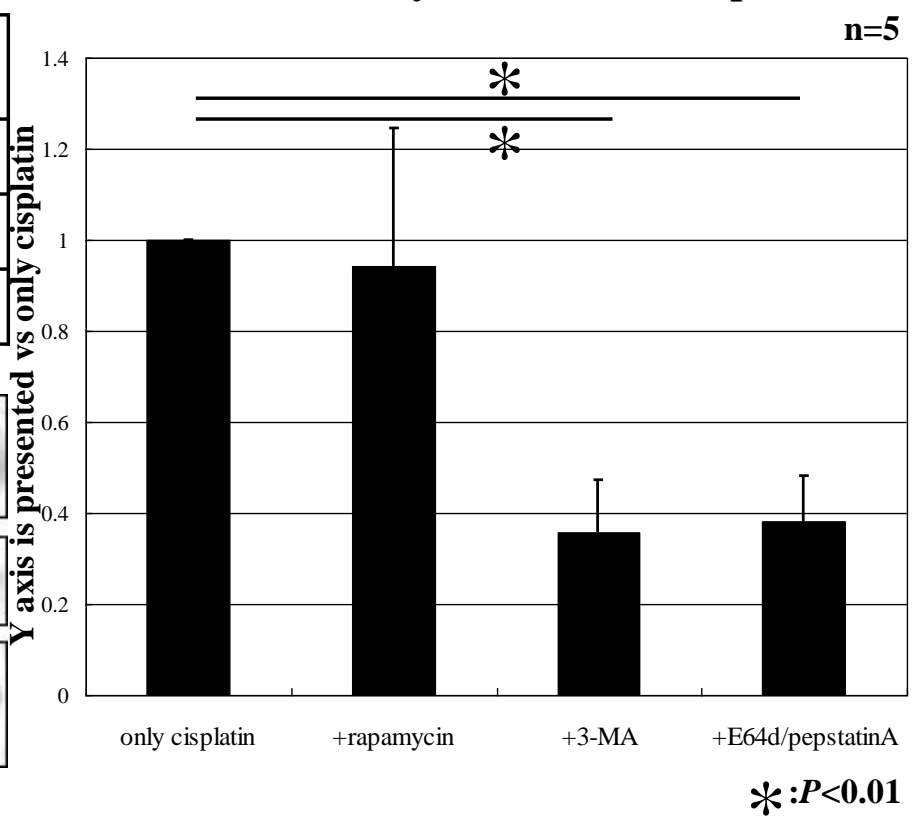

\begin{tabular}{|c|cccc|}
\hline cisplatin & + & + & + & + \\
\hline rapamycin & - & + & - & - \\
\hline 3-MA & - & - & + & - \\
\hline E64d/pepstatinA & - & - & - & + \\
\hline
\end{tabular}

\section{LC3 I ( 18 kd ) \\ LC3 II ( 16 kd )}

cleaved caspase 3 ( 17 kd )

actin ( 42 kd )

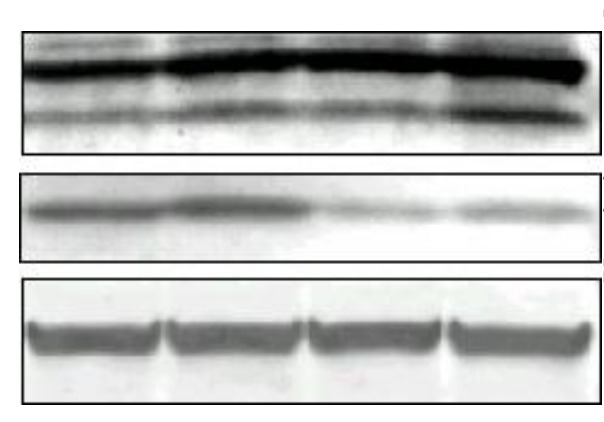

$*: P<0.01$ 

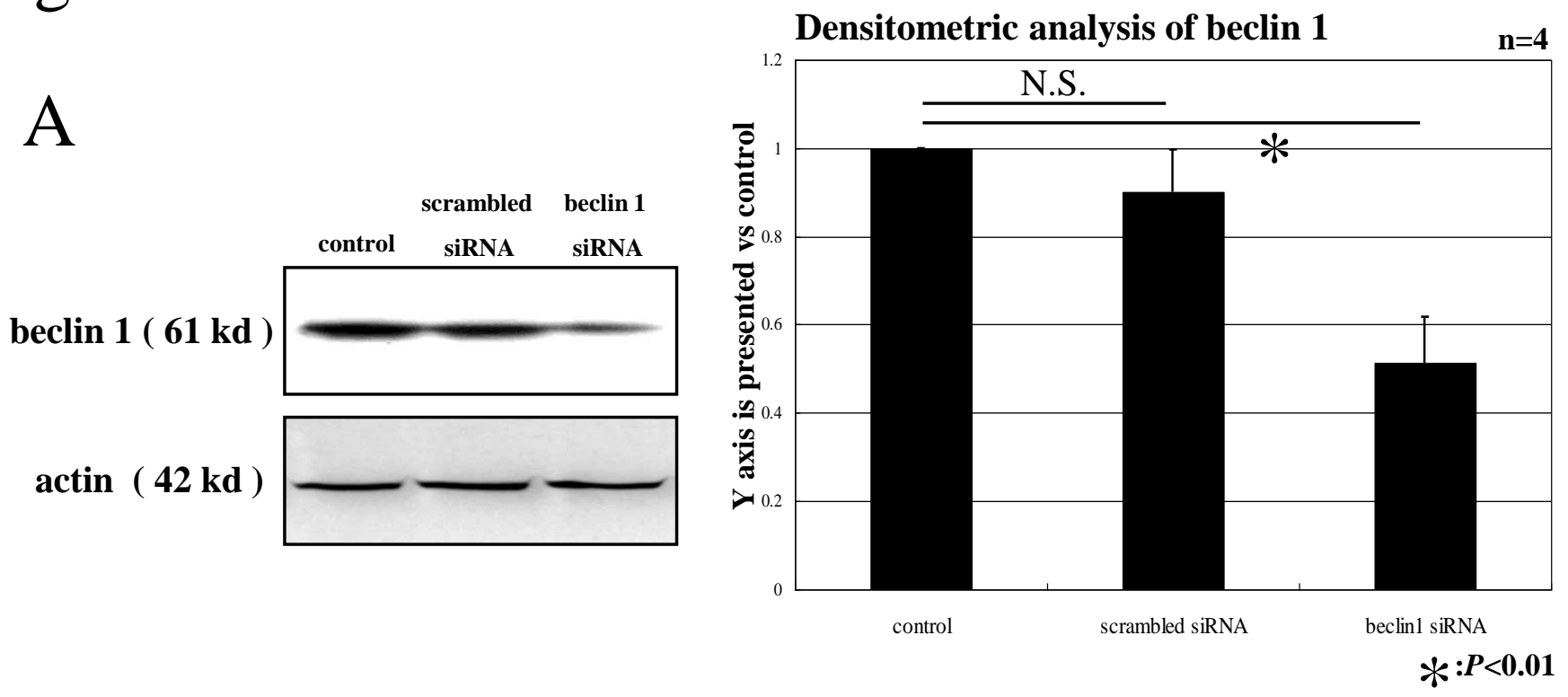

B

\begin{tabular}{|c|cccccc|}
\hline cisplatin & - & - & - & + & + & + \\
\hline scrambled siRNA & - & + & - & - & + & - \\
\hline beclin 1 siRNA & - & - & + & - & - & + \\
\hline
\end{tabular}

cleaved caspase 3

( 17 kd )
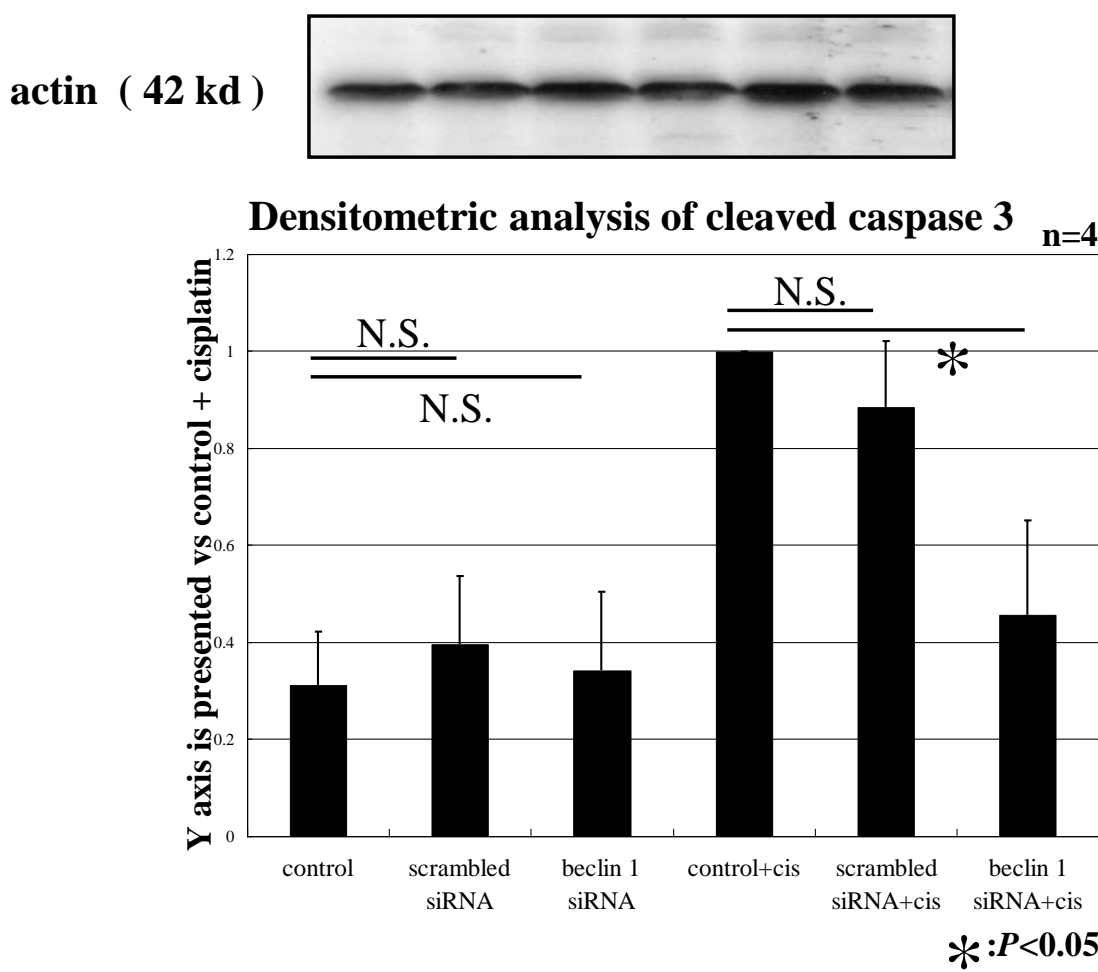